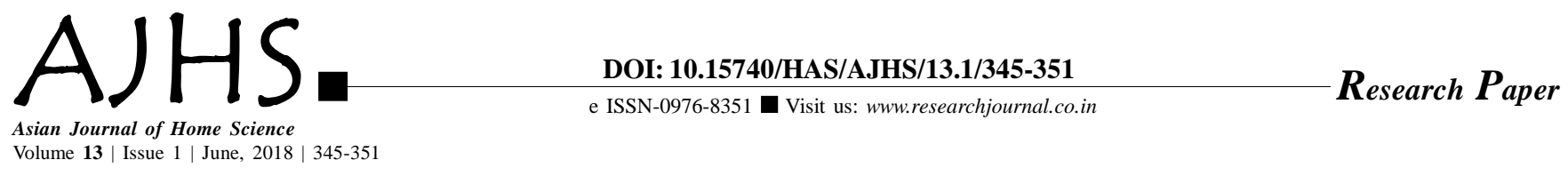

\title{
Commercialization of Cassia gums in eco-printing of textiles
}

Jyoti V. Vastrad and Vidya V. Sangannavar

Received: 10.11.2017; Revised: 24.04.2018; Accepted: 11.05.2018

See end of the paper for authors' affiliations Jyoti V. Vastrad

All India Coordinated Research Project of Home Science

(Clothing and Textile), Main

Agricultural Research Station,

University of Agricultural

Sciences, Dharwad (Karnataka)

India

Email : jyotivastrad@gmail.com
DBSTRACT : Printing is one of the traditional fabric decoration techniques and a creative art nurtured and patronized through centuries. Textile printing is one of the processes of textile industry that causes very high water pollution due to unfixed colour, thickening agent and other ingredients of printing paste which are washed off from the fabric into natural water bodies. An increasing awareness about the realization that the intermediates and chemicals used in synthetic dyes being toxic and hazardous to human health as well as to the environment has led to the increase in demand for nontoxic eco-friendly materials. Hence, in the present study, keeping in view the importance of natural gums in apparel and textile industry, an attempt was made to print the fabric using naturally prepared gum. The printed fabrics were utilized for construction of clothing and home textiles, which were assessed for the acceptability. Questionnaire was designed on five point scale to obtain relevant information from the thirty respondents. The results showed that all the entire natural printed products were highly preferred and appreciated by the respondents.

KEY WORDS: Block printing, Screen printing, Cassia tora, Thickener

- HOW TO CITE THIS PAPER : Vastrad, Jyoti V. and Sangannavar, Vidya V. (2018). Commercialization of Cassia gums in eco-printing of textiles. Asian J. Home Sci., 13 (1) : 345-351, DOI: 10.15740/HAS/ AJHS/13.1/345-351. Copyright@ 2018: Hind Agri-Horticultural Society. 